\title{
Writing Competences in Norwegian Vocational Education and Training: - How Students and Apprentices Express their Professional Competences
}

\author{
Ellen Beate Hellne-Halvorsen ${ }^{1}$ (D) $\cdot$ Leif Christian Lahn ${ }^{2} \cdot$ Hæge Nore ${ }^{1}$
}

Received: 5 June 2020 / Accepted: 21 December 2020/ Published online: 24 February 2021

(C) The Author(s) 2021

\begin{abstract}
This article analyzes the writing competence of Norwegian students and apprentices in three professions: Healthcare, industrial mechanics and electricians. The research forms part of a large-scale assessment project in vocational education and training (VET). A subset of 108 written test-answers were subjected to an explorative analysis focusing on generic and professional writing competencies. A more text-based and trans-contextual working life for many professions requires not only profession-specific communicative competency, but also a stronger engagement in generic literacy practices. The need for written communication with customers, clients and colleagues across workplaces and countries has increased and the use of understandable language when communicating with non-peers is required. In the study, we found that the generic writing competency declined during apprenticeship, but on the other hand that the use of professionalspecific terminology increased. We also found that writing competence seemed to be contextualized according to different traditions, text cultures and discourses across the three professions. The article questions the prevalence of text-based examinations in VET and analytical categories for measuring writing competence that do not take into account a multimodal character of professional communication.
\end{abstract}

Keywords Generic and professional writing competencies · Text composition analysis · Vocational education and training · Case-based test · Writing as key competency

\footnotetext{
Ellen Beate Hellne-Halvorsen

ehalvors@oslomet.no

Leif Christian Lahn

1.c.lahn@iped.uio.no

Hæge Nore

hnore@oslomet.no
}

Extended author information available on the last page of the article 


\section{Introduction}

Textualization, digital transformation and new technologies characterize all sectors in today's global society, and communicative competence ${ }^{1}$ has been acknowledged as a key productive resource in work and professional practices (Bétrancourt et al. 2016; Gee and Hayes 2011). Almost all professions require reading and writing skills to plan and document work processes (Karlsson and Nikolaidou 2016). Thus, professionals are increasingly expected to keep themselves up to date, and to "learn to learn" by integrating literacy skills and professional competence. These combinations are often referred to as "hybridity" (Davey and Fuller 2013; Nore 2015) and regarded as essential themes within educational systems and professional life. They are fundamental elements of the international competence-based educational reforms (Mulder 2017) that have accentuated the integration of basic skills (i.e., writing, reading, oral communication, mathematics and digital skills) as part of learning outcomes in all school and vocational subjects. These ideas are implemented in the Norwegian system for vocational education and training (VET) through the Knowledge Promotion Reform (2006, 2020 revision), (Baek et al. 2018) which is characterized as a literacy reform (Hertzberg and Roe 2015).

Textualization as a "new work order" (Gee et al. 1996) has been a research topic for 20-30 years, but is still leaving us with a number of unanswered questions: To what extent does this "work order" differ between vocations and professional boundaries? How is the differential digitalization of workplace communication and performance incorporated in extant models of "writing in the workplace" (Schrijver and Leijten 2019)? What are the mechanisms of work-place learning and vocational ${ }^{2}$ training given such transformations? It is beyond the scope of our study to provide satisfactory answers to these "grand" issues, notably the last one. We have focused on the first with sidelong glances to the second. The third issue has a directive function for our research. This article is based on a study of writing skills among students and apprentices in Norwegian VET representing three professions; healthcare workers, electricians and industrial mechanics.

\section{Aims and Research Questions}

Our empirical material is drawn from a national research project, Measuring Vocational Competence Development (MECVET), that piloted the implementation of a German model and instrument, COMET-model, for large-scale assessment in VET (Lahn and Nore 2019; Rauner et al. 2013). In our review of the psychometric results and interviews with raters (from schools, work and labor unions) we were intrigued to pursue in an explorative way the correspondence between scores on professional competence and indicators of proficiency in writing. The COMET test assignments were formulated as work orders (from clients, superiors, colleagues etc) to which the students and apprentices responded in a written note. The validity of such formats is an

\footnotetext{
"The term "competence" is used as mass noun and "competency / competencies" as count nouns when referring to subcategories or dimensions of the more general "competence".

${ }^{2}$ The term "Vocation(al" is used when referring to specific subjects / disciplines in VET (confer German "Fach") - and the title/name of the educational level. Otherwise "profession(al)" is used (confer German "Beruf").
} 
underlying issue in this article, but methodological challenges with the implementation of the COMET-model in a Norwegian context do not invite a psychometric inquiry at this stage (confer Lahn and Nore 2019). Our strategy in the present study has been to select a subset $(\mathrm{N}=108)$ of written test answers and subject these to a rerating using a test instrument for the assessment of writing competencies. Our analysis which is basically qualitative, has been guided by three main research questions:

1. How does the VET-students' and apprentices' writing competencies relate to their specific professional writing skills and generic writing skills?

During the first screening of our test-data we were struck by the distinct differences between writing competencies, genre or discourses across professions and domains. In line with the constant comparative method (Charmaz 2014) and new literature on professional genres in workplace-writing (Neumann 2016), the following question was therefore raised for systematic inquiry:

2. In what ways are writing competencies similar and/or different across professions?

Our research has been designed to compare cohorts of students and apprentices in the three trades across three years in the Norwegian model of sequential dual VET, the second year in school followed by the two years in working-life as apprentices. Thus, we have been able to pursue a third research question:

3. How does the writing competencies change during the school period, the apprentice period and in the transition from student to apprentice?

We have explored these questions from two main perspectives; one considering the professional use of language, such as terminology and specific text culture and argumentation within professions. The other perspective includes the use of language as generic and transferable writing skills, such as orthography, punctuation, syntax and text organizing and paragraphs. However, this framework is extended by including exemplars of multiple literacy practices that fall outside traditional definitions of writing competencies.

\section{Measuring Professional Competence and Literacy in VET}

Different definitions and perspectives on literacy are identified in the international large-scale assessment instruments developed during the last two decades. For example, Program for the International Assessment of Adult (PIAAC) aims at measuring basic competencies and general problem-solving skills. It extends the scope of the previous International Adult Literacy Study (IALS) by focusing on digital media (OECD 2009). However, these tests are constructed in formats that support reading in a broad sense, but not the production of texts in written or graphic form. The Program for International Student Assessment (PISA) refers to its knowledge focus as "scientific literacy" (Sadler and Zeidler 2009) and has inspired the development of similar instruments for the measurement of domain-specific competencies in VET, for 
example the VET-LSA that was piloted in several European countries, including Norway (Baethge and Arends 2009). This literature on large-scale instruments underscores the difficulties in disentangling the concept of professional competence and that of literacy.

The COMET-model and instrument for measuring key dimensions of "holistic shaping competence" (Rauner et al. 2013) was piloted in China, South-Africa, Switzerland and Norway. As pointed out above, testees were asked to write a short note describing how they would handle a work order and provide arguments for their "solutions". The rationale for a written format is two-fold. Firstly, the above argument for a rich repertoire of communication modes in a changing working life, is emphasized. Secondly, Rauner et al. (2013), referring to central ideas in German work psychology, underline how writing has a learning potential in making explicit the planning and evaluation of work tasks. A similar concept of the writing process in three stages, planning, writing and reviewing, has a dominating position in the literature on writing (Heidrich and Schubert 2019) although recent versions give more leeway for situational and motivational factors (Parkinson et al. 2018).

In sum, our short review of the OECD international large-scale assessments for scholastic outcomes / adult competencies and similar attempts for the VET-sector indicates that the concepts of competency and literacy are often used interchangeably. However, such tests place little emphasis on the type of writing skills increasingly asked for in the formal assessment of students and apprentices (Nore \& Lahn 2014). Our study of written solutions in the MECVET assignments should be viewed against these international trends and more general discussions on the training of students' writing and literacy in different professions throughout VET.

Dual VET systems like the Norwegian, combine school-based and workplace-based training for both "hard skills" and "soft skills" such as domain-specific practical procedures and corresponding theory on the one hand, and professional behavior and communication standards on the other (Ortoleva and Betrancourt 2015). To complete a VET qualification, one must pass a trade or journeyman's examination with a long tradition as performancebased tests. However, the recent reforms give higher priority to writing skills supporting planning, evaluation and documentation of work tasks and processes as well as justifications of their profession-based solutions. In some professions, justifications and documentations may include a combination of writing and other semiotic resources such as photos or filling in pre-defined professional forms as multimodal texts. In other professions, as healthcare, texts are mainly verbal as students and apprentices are trained in writing case reports like the assignments of the COMET-test.

In the school-based part of Norwegian VET, students learn both vocation-specific subjects and general subjects like Norwegian language. School-subjects also include vocational in-depth studies in enterprises with logs on vocational experiences. After two years, students turn into two years of apprenticeship with mainly practical, professional training.

\section{Literature Review and Theoretical Framework}

When focusing on the writing competence of VET-students and apprentices we are confronted with the task of actively restructuring a literature that is split between 
different thematic perspectives (Heidrich and Schubert 2019) and theoretical positions with specific methodological preferences (Karlsson 2009). Research that surfaces terms such as "work-place writing" (Bremner 2017), "writing in the workplace" (Schrijver and Leijten, 2019) and "professional written communication" (Heidrich and Schubert 2019) has been dominated by studies of professionals that are specialists in document production, translation etc. This literature draws on the broader fields of professional expertise (Kellogg 2018) and Literacy for Special Purposes (Leijten et al. 2014). Research that more directly focus on the integration of literacy (writing) practices and work performance in the vocational professions is comparably sparse (Parkinson et al. 2018). A number of studies confirm the established theses on the textualization of "manual work" (Karlsson and Nikolaidou 2016) adding to this picture the transformative effects of digital technologies on written communication in everyday work settings - roughly understood as a change from linear textual production to hyper-texts and multimodality (Fraiberg 2018). These patterns are accentuated by the need for "interdiscursivity" (Breuer and Allsobrook 2019) in globalized professional work when written communication with customers, experts in various fields etc. is the "new work order" (Gee et al. 1996). Consequently, scholars differ in identifying "writing genres" attributed to specific trades or professional communities (Breuer et al. 2016) or focus on the ways written professional communication is hybridized (Davey and Fuller 2013). Such variation may reflect the unique character of the sites investigated.

A number of studies have illustrated how apprentices and trainees are encultured into a spoken professional discourse during their training. Less attention has been given to their learning writing skills (Parkinson et al. 2018). A similar neglect is identified in professional communities that recognize the value of writing competence as crucial resources for effective work performance, but that do not see the point of training such skills (Neumann 2016; Breuer et al. 2016). Writing activities in VET schools primarily mediate student learning and are only slightly oriented to the need of complex working life literacy (Hellne-Halvorsen 2014; Coppi et al. 2019). To make these practices relevant to the "interdiscursivity" (Breuer and Allsobrook 2018) of modern working life, written communication should be an integral part of VET combining genreinstructions and linguistic features such as vocabulary, orthography, syntax, sentence and text structure, coherence and argumentation. In a survey on the education of engineers and health professionals from the UK and Germany, Breuer et al. (2016) found that training for writing was partly absent and highly deficient. According to students' responses grammar or linguistic features were given the least attention by teachers and text genre instructions did not correspond to professional genres in working life. This mismatch is a point of departure when scholars argue for boundary-crossing programs (Breuer et al. 2016; Leu et al. 2017; Nägele and Stalder 2017) that strengthen students' work-based writing skills on one hand and turn these into resources for professional development and transferable language skills on the other (Bétrancourt et al. 2016; Ortoleva and Betrancourt 2015; Neumann 2016). Still, apprentices and trainees must learn from practice and collegial interaction to become proficient in workplace writing (Parkinson et al. 2018).

Our analytical approach to writing in VET is based on two theoretical frameworks: The first, informed by New Literacy Studies (Barton and Hamilton 1998; Heath 1983; Street 1984), underlines how specific competencies are intrinsically linked to the 
functions and purposes of writing. Semiotic resources, textual norms and use of professional terminology and argumentation should be analyzed through their anchoring in specific professions and text culture. Berge et al. 2016 define text culture as a rhetorical community "constituted by text norms defining what kinds of writing are considered relevant..." (p. 175)". From this perspective, even though writing is situated within a specific sociocultural context, written activities reflect the ecological and dialectical relations between community and writing practices. In principle, both teachers and trainers in the VET-system are considered experts on written discourses, textual norms, professional expressions and language use within their field. Thus, the assessment of written text should be based on these explicit textual norms (Berge et al. 2016, p. 175). Writing competence for professional purposes are in our study referred to as the professional factor (P-factor).

Our second analytical approach draws our attention to the way professional competence is communicated by ordinary language expressions and formal, standardized use of language - what we refer to as its generic character. In a working life characterized by "interdiscursivity", the generic (G-factor) and formal writing skills are characterized as decontextualized and boundary-crossing. They are at the core of professional expertise when different target groups and different purposes of writing demand the ability to transform writing skills throughout one's life as a transferable competency (Davey and Fuller 2013; Nägele and Stalder 2017; Nore 2015). Generic writing competencies includes skills in complex linguistic systems and grammar; text organizing, cohesion, paragraph, syntax, spelling and punctuation. In VET, this might be a challenge for teachers and trainers who: (a) may not regard writing as part of their teaching and training, and/or (b) may not themselves have the competence or attitude required to teach students and apprentices generic writing skills (Hellne-Halvorsen 2014). Research has shown that many VET-teachers and trainers do not have the vocabulary or metalanguage to teach or guide students and apprentices in writing (Evensen et al. 2016).

Our approach to writing competence in VET indicates a double perspective; one relates to a vocational profession within a specific context, text culture or discourse, while the other relates to generic skills across contexts, subjects and professions, what we term transversal or generic writing skills. In line with the theoretical frameworks outlined above we adopt a broad definition of literacy as the ability " (...) of putting knowledge, skills, attitudes and values effectively into action when dealing with (handwritten, printed or digital) text in the context of ever-changing demands" (Hanemann 2015, p. 5). This definition draws on a multidimensional construct that includes language, multimodality, text culture, professional communication and represents a holistic approach to language and literacies (Coppi et al. 2019; Fraiberg 2018; Jewitt and Kress 2003). By implication, a new literacy pedagogy has gained currency in part by acknowledging the urgency and learning potential of media multiplicity and convergence (Schwendimann et al. 2018). The differentiation of codes and mediated practices should be reflected in the pedagogical discourses on the variety of functional writing competencies. However, elements of "hybridity" and transversal writing norms need to be considered as pointed out above.

The learning potential of teachers' and trainer's assessment of written assignments or "learning logs" and their feedback to students and apprentices is a recurrent research topic (Schwendimann et al. 2018). It will not be addressed in our review, but indirectly the presented literature and theoretical framework raise important questions about the 
professional writing norms and practices to be explicated for different educational purposes and in various formats (Karlsson 2009). We return to this topic when the set of categories included in the Professional Writing Manual is explained in the next part, and in our final reflections.

\section{Method}

In this section, we provide added information on the COMET-test in terms of samples and the test assignments. Then we discuss the selection-criteria for our subset of written test answers to be rerated with the Coding Manual for Professional Writing and provide an overview of the general categories and the specific categories chosen for the study in this article.

\section{Description of Test Design and the Subset for Analysis}

The COMET-testing was conducted at three different stages: At the end of the second year in upper secondary school, at the end of the first year and the second year of apprenticeship ( $\mathrm{N}=50$ in each stage and within each profession, in total 450 students and apprentices). The testing followed the guidelines of the COMETproject by providing a set of four test assignments for each vocational profession representing core work tasks in each of the professions and formulated as complex problems or orders from customer and enterprises. Realistic situations specific for each vocational profession were described, such as planning an outdoor day with elderly patients (Healthcare), outlining a repair and maintenance solution to a machine breakdown (Industrial mechanics) or suggesting an electric wiring in a drying room for spray-painting (Electricians). The task assignments asked for a similar professional argumentation structure for the three professions, which included writing to inform, explain and describe, or a justification for a claim (Andrews et al. 2009). Example from healthcare: "Describe and give reasons for...". From industrial mechanics: "Elaborate and give reasons for", and electricians: "Suggest solutions and give reasons for...". These formulations provide general guidelines for identifying both a reader (Berge et al. 2016) and an implicit target group such as customer, or superior. These norms may have guided testees' performance on the test and should be considered when analyzing the material. The testees were given two hours to write their assignments using computers with access to the Internet - the latter violating the international guidelines for the large scale assessment with COMET.

108 written answers from the COMET-material were selected for the analysis based on the following criteria: (1) 12 students and apprentices in each vocational profession at each educational stage, (2) all four test-assignments represented at each stage, (3) answers representing different professional competence levels as rated by experts in the trade. The researchers undertaking the rating of writing skills were not told how the selected written hand-ins scored on the professional competence assessment. The testees were given information about the assessment criteria used in the COMET-rating but not about the criteria of writing 
competence. However, one of the key dimensions of the total COMET-score for professional competence was the quality of their written presentations.

The empirical basis of this article is the analysis of a subset of the COMET written test answers, using a coding system that (1) focus on formal/generic writing skills and 2) specific professional characteristics of working life literacy. In accordance with our theoretical framing, we studied professional competence as a conjoint use of professionspecific language (P-factor) and more general words and expressions, characterized as generic written competency (G-factor). However, our analytical perspective needs to include characteristics of writing skills that may facilitate the communication of professional competencies. In order to strengthen the consistency of our interpretations, nearly half of the written answers to the test were subject to discussion between the coders. Discrepancies in rating were most evident for categories such as terminology and professional argumentation, with more consensus on the generic writing skills.

\section{Analytical Codes}

As stated above, our approach indicates a socio-cultural and broad perspective on literacy, which also applies to our understanding of the term "text". A broad perspective implies both verbal language and other semiotic resources that writers employ in their text production such as figures, drawings and copies of illustrations from Internet, as visual language (Coppi et al. 2019). If a text, as an utterance gives meaning and status to participants within a context, it is reckoned to be a text (Halliday 1973). The students and apprentices in our study could, for example, use verbal language coupled with drawings, copies of illustration, pictures or figures from Internet.

The way testees understand the reading of the assignment, their professional writing styles and multimodal composing may have had impact on the length of the test assignments, and thereby the rating of their professional and writing competence. To assess the students and apprentices' professional competencies, it is essential to analyze their texts in the broadest sense of the term, including a variety of semiotic resources. However, our analysis has mainly focused on the use of verbal language which is reflective of the "state of the art" when it comes to instruments for assessing writing competence in a digitalized working-life.

\section{Categories for Analysis}

Our analysis is based on two perspectives; profession-specific writing competency (P-factor) and generic or formal writing competency (G-factor). Considering the complexity of written texts, a coding scheme for analyses of the assignments was developed including categories for the two perspectives based on established textand language analysis in general language subjects at upper secondary level in school. Profession-specific writing includes professional terminology, professional related terminology, professional argumentation, professional text culture and multimodality. Generic or formal writing skills includes categories such as orthography, expressions and grammar, punctuation, syntax, paragraph, text coherence and text organization. In this article, we outline a selection of these categories as shown below (Table 1): 
Table 1 Explanation of sub-categories of written competence according to our analytical approach (Evensen et.al. (2016)

Professional specific written competency (P-factor) Generic written competency (G-factor)

Professional text-culture:

Text-culture is connected to specific text-norms within a domain, as use of keywords, points or prose-presentation combined with other semiotic resources (Berge et.al. (2016).

Terminology:

Use of specific professional terminology not common in other professions.

\section{Professional argumentation:}

Use of keywords or sentences that explain, give reasons for or elaborate a statement.
Orthography / spelling:

Misspelling of single words and compound words. Compound words are a productive way of making new words in Norwegian language.

Syntax and punctuation: Mistakes in punctuation as commas and full stop/period. Syntax is closely connected to punctuation, but also to incomplete / deficient sentences, unclear references, sentence variation, start of sentences.

Text organizing and paragraphs: Coherent organizing at macro level of text. Paragraph design - related to graphic issues, to logic and semantics and to information structure within a paragraph.

The analytical strategy of each category is mainly based on a highly reliable counting of grammatical mistakes such as lack of commas, or misspelling. This is also the case of using professional terminology. Harder to analyze is categories of professional argumentation and text organization. Classification in low - medium - good argumentation needs further explanation (Table 2):

Table 2 Examples of criteria on the performance levels low - medium - and good in argumentation

\section{Performance Criteria and examples}

level

Low $\quad$ Copy from test task: part or sentences from the test task without any independent argumentative reflections (Healthcare)

- Statements or claims without further explanation such as: "Heat pump is recommended if you want heating" (Electrician). $\rightarrow$ Nothing about why heat pump, or comparison of alternatives

Medium - Argumentation, but weak explanation: "Motivate to use for instance a walker instead of a wheelchair. Then she can use the resources she has and maintain them". (Healthcare)

$\rightarrow$ Nothing about why a walker, how to motivate, what kind of resources or how to maintain them.

Good Argumentation by using more than one sentence/explanation and often with a problematizing perspective:

"The family can also consider using electric power from the sun by solar system. It can, for sure, be expensive to buy solar panels, but over time, they will save money on producing electricity they use themselves. When they are not using the cottage, solar panels can be connected to battery which will be loaded". (Electrician) 
Argumentation can be performed by coherent prose, by bullets or by fragmented sentences. Essential argumentative criteria are logical and coherent explanation to a statement or claim. The criteria are directive but depend on assessors' judgement.

\section{Results and Analysis}

In the following presentation of results from the assessment of writing competency we first provide examples of noticeable variations in the written answers. Then a crosstabular summary is provided for each category and integrated with analytical perspectives.

\section{Professional Specific Writing Competencies and Text Cultures}

Professional writing competence is essential for participation in expert communities and professions. In general, students and apprentices learn and internalize professionalspecific terminology and expressions during VET. Thus, they reproduce a text culture.

Text-cultures within specific professions or expert domains are characterized by literacy markers, for example differences in the use of semiotic resources and text organization (Coppi et al. 2019; Leu et al. 2017; Neumann 2016; Parkinson et al. 2018). Likewise, the textual layout varies from: (a) versions of coherent text in prose, (Excerpt 1), (b) presenting text as bullets with keywords and fragmented sentences, (Excerpt 2), to (c) frequent use of filling in pre-defined professional forms, (Excerpt 3). As illustrated below, our study shows different ways to organize and construct texts across these three vocational professions.

Tine Olsen was an orienteer as a young person and talks a lot about walks in the forests. But she is dependent on a walker and I would have talked to both Tine and her relatives about the forests and the conditions for a walker there. If the conditions are okay, the activity day could be arranged in this forest. Tina would probably be happy to come to a forest she remembered from her youth.

Rolf Larsen has dementia but is doing well physically. He loves fishing and smiles well when he sees pictures from fishing trips in the good old days. He would love to watch some fishing boats, and maybe later get some fish from the grill.

Excerpt 1 Healthcare: Coherent prose

\section{Dismantling of the transmission belt}

- look for the job, and have it accepted by operation,

- lock with padlock on the control panel, electric check of the engine

- try starting the engine in order to double check that it does not start before I start working on it

- prepare tools and equipment for work

- drain the gearbox for all oil

Excerpt 2 Industrial mechanics: Bullet points 


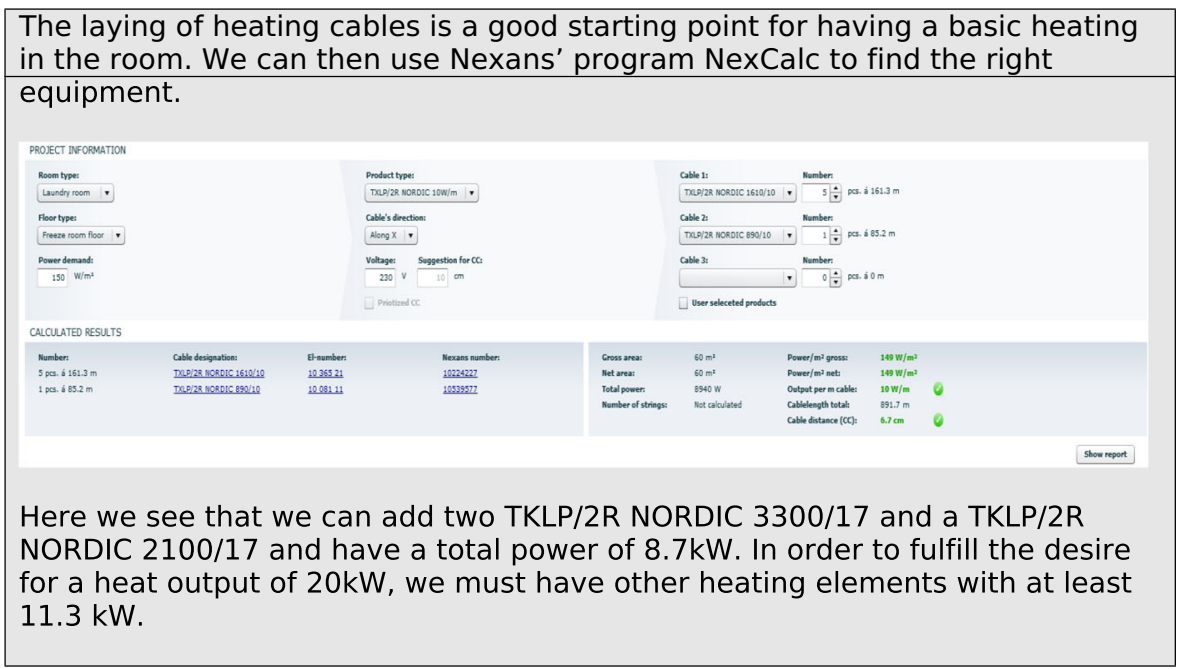

Excerpt 3 Electricians: Use of verbal language in combination with semiotic resources from Internet.

In Table 3, we make an analytical distinction based on verbal language, between coherent prose, fragmented sentences and multimodality (combination of verbal language and illustrations, drawings, pictures). The figures reflect the dominant pattern. For each category of text formation, we have one column for students (S) and one for second year apprentices (A).

Within all professions, coherent text formation is the dominant pattern. Healthcare workers' hand-ins are expressed in purely verbal form, while both the industrial mechanics and especially electricians use other semiotic resources combined with verbal language. One explanation can be traced back to the tests constructed as cases of authentic work tasks. Another factor that distinguishes between the professions is the style to which the students and apprentices are most exposed to in their training - healthcare students and apprentices write predominantly in coherent prose, whilst industrial mechanics and electricians more often use sentence fragments, keywords and bullet points - increasingly so during their apprenticeship period (Table 3).

Another significant difference between the professions is that students and apprentices in healthcare write longer texts than those in the two other professions. Both healthcare workers and electricians in their $2^{\text {nd }}$ year of apprenticeship use

Table 3 Text-culture: Text-formation within vocations, students (S) and second year apprentices (A)

\begin{tabular}{llll}
\hline Professions & Coherent prose & $\begin{array}{l}\text { Fragmented sentences / } \\
\text { keywords }\end{array}$ & $\begin{array}{l}\text { Multimodality: Use of language } \\
\text { and other semiotic resources }\end{array}$ \\
\hline Healthcare worker & $75 \%(\mathrm{~S})-92 \%(\mathrm{~A})$ & $25 \%(\mathrm{~S})-8 \%(\mathrm{~A})$ & $0 \%(\mathrm{~S})-0 \%(\mathrm{~A})$ \\
Industrial mechanic & $82 \%(\mathrm{~S})-58 \%(\mathrm{~A})$ & $18 \%(\mathrm{~S})-42 \%(\mathrm{~A})$ & $2 \%(\mathrm{~S})-3 \%(\mathrm{~A})$ \\
Electrician & $70 \%(\mathrm{~S})-66 \%(\mathrm{~A})$ & $30 \%(\mathrm{~S})-34 \%(\mathrm{~A})$ & $8 \%(\mathrm{~S})-5 \%(\mathrm{~A})$ \\
\hline
\end{tabular}


more words than students do, whereas this difference is not present in the scores of the industrial mechanics.

\section{Professional Terminology}

Frequent use of professional specific words or terminology differs between professions. Table 4 give some examples of professional-specific terminology within each profession.

Table 5 shows the percentage of profession-specific terminology per page in three clusters $(<6,7-14$ and $>15)$.

As we can see, healthcare students and apprentices use less professional terminology than electricians and industrial mechanics. Whereas the latter use more professional specific terminology in their last year as apprentices compared with their school period, the reverse is true for the healthcare candidates.

\section{Professional Argumentation}

Argumentation or to argue are conceived broadly as encompassing written activities such as explaining, proving, documenting, giving reasons or examples for statements (table 2). They are common across disciplines or subjects (Andrews et al. 2009; Breuer et al. 2016). Professional argumentation makes logical reasoning explicit. In Norwegian education (primary and upper secondary school), the ability to argue is emphasized as part of democratic participation and critical thinking. This is also the case in VET and in VET-teachers' didactical orientation towards student writing (Hellne-Halvorsen 2014). Through argumentation, students and apprentices prove their professional competence and understanding.

As we have stated above, the COMET case assignments asked the testees to give reasons and argue for their solution. In Table 6, professional argumentation in the three professions are compared on three levels (low, medium, good) (See also Table 2).

Students and apprentices in healthcare perform somewhat better than industrial mechanics in professional argumentation. According to the examples of solutions illustrated above (Exerpt 1-3), healthcare workers use coherent prose as argumentation strategy and industrial mechanics use chronological bullets. Electricians on the other hand, are in sum rated at medium and low level of performance in

Table 4 Examples of professional-specific terminology

\begin{tabular}{lc}
\hline $\begin{array}{l}\text { Professional-specific } \\
\text { terminology }\end{array}$ & Examples \\
\hline Healthcare worker & $\begin{array}{r}\text { Life quality, care needs, walker, rehabilitation, community worker, day } \\
\text { center, short-term stays, hip fractures, balance problems, coordination }\end{array}$ \\
Industrial mechanics & $\begin{array}{r}\text { Pneumatic, cylinder, piston, telescope, axle, mounting position, alloy, } \\
\text { bearings, chain case, jack } \\
\text { Blectrician }\end{array}$ \\
$\begin{array}{c}\text { Breakers, extension cords, cable, power meter, voltage drop, thermostat, } \\
\text { heat pump, conduction }\end{array}$
\end{tabular}


Table 5 Percentage use of terminology per page, for each professions, students and apprentices together

\begin{tabular}{llll}
\hline Professions & Less than 6 & Between 7 and 14 & More than 15 \\
\hline Healthcare worker & $58 \%$ & $39 \%$ & $3 \%$ \\
Industrial mechanic & $17 \%$ & $29 \%$ & $54 \%$ \\
Electrician & $15 \%$ & $39 \%$ & $46 \%$ \\
\hline
\end{tabular}

professional argumentation which may be due to their use of verbal language in combination with illustrations and drawings, as multimodal texts. However, our analysis of professional argumentation of the test hand-ins indicates that their use of figures is not adequately supported by verbal language.

Table 7 gives an overview of professional argumentation skills across educational stages, from student to last year apprenticeship. To what extent do the two learning contexts, (school and workplace) influence the development of professional argumentation? Table 7 illustrates the development of professional argumentation during VET for the three professions by comparing students in school and second year apprentices.

The ability to argue professionally in written form seems to be at an average level for students in school context, except for the electricians who score remarkably high on this factor. Healthcare apprentices show a relatively poor argumentative competency compared to healthcare students whereas an opposite tendency is evident for the apprentices in industrial mechanics and electricians. These apprentices seem to improve their argumentation skills to a medium level. When it comes to argumentation skills at a good level, apprentices in all the three professions show a decreasing competence to argue professionally.

\section{Generic Written Competence}

Generic writing competency includes different aspects of formal language skills in general and reckoned as key competencies in communication and learning in education and working life (Breuer et al. 2016; Nägele and Stalder 2017). First, generic competencies implies the ability to communicate with different target groups, e.g. make the content and message of a written text clear and understandable to both peers and nonpeers. Next, to avoid misunderstanding and deficiency in communication, which demands adequate formal skills. Overall, generic competencies is required and necessary to impart or communicate professional competency. Shortages, misspelling or grammatical failure can interfere with productive professional communication.

Table 6 Professional argumentation within each profession, students and apprentices altogether

\begin{tabular}{llll}
\hline Professions & Low & Medium & Good \\
\hline Healthcare worker & $28 \%$ & $33 \%$ & $39 \%$ \\
Industrial mechanic & $27 \%$ & $44 \%$ & $29 \%$ \\
Electrician & $39 \%$ & $52 \%$ & $9 \%$ \\
\hline
\end{tabular}


Table 7 Professional argumentation skills at different VET-stages

\begin{tabular}{llll}
\hline Professions and contexts & Low & Medium & Good \\
\hline Healthcare worker: school context & $33 \%$ & $42 \%$ & $25 \%$ \\
Healthcare worker: 2nd year apprentices & $80 \%$ & $20 \%$ & $0 \%$ \\
Industrial mechanic: school context & $25 \%$ & $42 \%$ & $33 \%$ \\
Industrial mechanic: 2nd year apprentices & $27 \%$ & $55 \%$ & $18 \%$ \\
Electrician: school context & $25 \%$ & $17 \%$ & $58 \%$ \\
Electrician: 2nd year apprentices & $17 \%$ & $75 \%$ & $8 \%$ \\
\hline
\end{tabular}

\section{Orthography and Spelling}

Students and apprentices in our study used computers with an Internet connection to write their solutions. They therefore had the possibility to use a spellchecker. Despite this, misspelling occurred in most texts. In our study, we separate misspelling in two different categories; single words and compound words. Compound words are a Scandinavian and German phenomenon, and an expanding and productive way of making new words in our language, indicating that the use of hyphenated words is not very common. Using spellcheck can be of great help for single words. However, spellchecker does not always correct compound words, since the spellchecker mistakenly marks many of these words as incorrect way of spelling. We have simplified the presentation by combining the misspelling of both single and compound words.

We found that the students perform better than the apprentices and the second-year apprentices commit more spelling errors than first year apprentices. The healthcare students and apprentices perform better in orthography than the other groups, whereas students and apprentices in electrician range lowest on this factor. The increase in misspelling across the three educational stages crossing the school-to-work boundary is noteworthy.

\section{Syntax and Punctuation}

A well-formed sentence structure in professional texts should fulfil certain criteria. First, a sentence must formally contain a grammatical subject and verb usage that makes it clear and explicit who or what a sentence is about and how the subject is related to action. An incomplete or deficient sentence is not a sentence in our analysis but is counted as a sentence fragment. Exceptions from this are formulations in keywords and bullets, which are present in several texts. Secondly, each sentence has to start with a capital letter, and finish with a period punctuation. Many very short fragmentary sentences or very long sentences without periods also indicates weak competence in sentence formulation. Sentence variation and coherence between sentences shows the ability to formulate good sentences. Above all, each sentence must express a clear and understandable content.

Healthcare students and apprentices are considerably better at sentence formulation compared with the two other professions ("Good" scores for 72\%, 54\% and 58\% respectively). Industrial mechanics and electricians show more or less similar performance due to bullets and fragmentary sentences. Competency in formulating good sentences decreases as the testees move from their school contexts (where 85\% write good 
sentences), to their work contexts (where only $50 \%$ of the second- year apprentices obtain such scores).

Punctuation is connected to sentence formulation in general. The use of periods (full stop) and commas can have impact on the content of a sentence, and thereby the communication of meaning and intention. Norwegian language is characterized by quite clear grammatical rules concerning the use of commas and is thus an issue of teaching in mother tongue/native language for all students at all stages in school. Our figures show that about $50 \%$ of the healthcare workers and industrial mechanics and $30 \%$ of the electricians had a maximum of one punctuation mistake per page. The differences between the students in the three professions compared to apprentices are minor; with 2-5\% more mistakes per page for the latter group, which is a small decrease in generic written competencies.

\section{Paragraphs and Text Organizing/Structure}

The macro level of professional texts in general normally contains several paragraphs and a logical stringency structure. This means that different parts of the content stick to the thematic issue of the whole text, and that each paragraph contains separate and different thematic issues or argumentative parts. The test assignments demanded explanation of case solutions. This indicates a logical and chronological structure of the written texts, illustrating the working processes, which can be realized in two ways: By coherent prose, by bullet pointing or by employing other multiple semiotic modes to the case solutions (see excerpts 1, 2, 3 and Table 3). In short, texts by healthcare students and apprentices are characterized by coherent prose, while texts of electricians and industrial mechanics combine prose with bullets, keywords or other semiotic resources. This is a matter of text culture or discourse.

Our assessment of text structure encompassed the ability to create a coherent structure. Table 8 shows a relative even distribution of levels (low, medium, good) across the professions - with a slightly higher score for healthcare workers and slightly lower score for the electricians.

However, when the results for all groups are compared across the three-year span, we find an improvement in scores for coherent structure - from $16 \%$ for students, $23 \%$ for first year apprentices and $47 \%$ for second year apprentices.

The ability to separate and structure a professional text in logical and coherent paragraphs is of course a matter of genre. The test assignments demand a logical structure preferably organized in paragraphs reflecting the different stages of working processes. However, writing paragraphs is related to prose presentation, and is not relevant for those few students/ apprentices who use only keywords or bullets in their texts. To organize a text in paragraph

Table 8 Ability to write coherent text structure (students and apprentices together)

\begin{tabular}{lllr}
\hline Professions & Low & Medium & Good \\
\hline Healthcare worker & $33 \%$ & $33 \%$ & $34 \%$ \\
Industrial mechanic & $20 \%$ & $51 \%$ & $29 \%$ \\
Electrician & $37 \%$ & $38 \%$ & $25 \%$ \\
\hline
\end{tabular}


Table 9 Ability to write logical and coherent paragraphs (students and apprentices together)

\begin{tabular}{lllr}
\hline Professions & Low & Medium & Good \\
\hline Healthcare workers & $28 \%$ & $36 \%$ & $36 \%$ \\
Industrial mechanics & $37 \%$ & $37 \%$ & $26 \%$ \\
Electricians & $33 \%$ & $55 \%$ & $12 \%$ \\
\hline
\end{tabular}

requires also an experienced writer, which many VET-students and apprentices are not. A paragraph marks off a text structure or a separate issue or content introduced by thematic sentence(s) to the rest of the paragraph, but still linked to the whole text. However, based on the figures in Table 9 it is tempting to conclude that making coherent and logical paragraphs seems to be a challenge for all testees.

As we see, the healthcare students and apprentices manage to write more comparatively 'good' paragraphs. Again, electricians rank lowest on this factor. When distributing the groups across educational stage we see an interesting improvement from nearly $20 \%$ of the students obtaining good scores, to nearly $30 \%$ for the first- and second-year apprentices. In addition, the medium scores have increased. This may indicate an improvement of professional competency in general, or it may reflect a deeper professional understanding and possibly a stronger motivation for professional writing on thematic issues in a logical and coherent form.

\section{Summary and Discussion}

The issue writing competencies surfaced during the MECVET-implementation of the COMET-model aiming at the measurement of holistic vocational competence in VET. First, in the theoretical rationale (a plan-write-reflect model) for written answers to casestudy assignments. Second, an observed high correspondence between scores on the COMET-test and the quality of the written solutions. These issues were never addressed in the international reports from national large-scale assessments (Rauner et al. 2013).

In this article we have been focusing on the written answers of students and apprentices in the three professions as literacy achievements without making any inferences about their validity as representations of professional competency or as adequate reflections on the assigned task. With such an analytical frame we conclude that writing competency in general (both professional specific and generic writing competencies) improves during the important VET-transition from the school context to the second year of apprenticeship. However, most of the students and apprentices score only at a medium level, as shown in Table 10:

Table 10 Overall assessment of writing competency, including both professional and generic writing skills

\begin{tabular}{llll}
\hline Stage & Low & Medium & Good \\
\hline School context & $49 \%$ & $39 \%$ & $12 \%$ \\
1. year apprentices & $38 \%$ & $36 \%$ & $26 \%$ \\
2. year apprentices & $17 \%$ & $45 \%$ & $38 \%$ \\
\hline
\end{tabular}


Second year apprentices are close to finishing their education and achieving trade certificates. Since more than $90 \%$ will pass, the candidates nearly have obtained the required professional competency, and in our study also improved their general writing competency.

On the other hand, we have identified a decline in generic writing skills. Students master generic skills like orthography and sentence formulation better than second year apprentices. A plausible explanation is that school subjects put more emphasis on writing formats in general compared with workplace activities. Frequent writing may improve writing competence. In addition, language teachers (teachers in Norwegian subject) have a specific perspective on generic skills, which may influence students' awareness on formal use of language. However, VET-teachers tend to pay little attention to generic skills and emphasize the profession-specific part (HellneHalvorsen 2014, 2019; Breuer et al. 2016). Overall, school contexts appear to have a positive impact on generic writing competency.

A school context also appears to emphasize professional argumentation. The ability to argue decreases with apprenticeship. VET-teachers are concerned about assessing students' written and oral argumentation as professional key-competencies and understanding. These findings are in line with former research on teachers' didactical work with professional argumentation in school context (Hellne-Halvorsen 2014). Incompany trainers emphasize task orientation and are less concerned about professional writing competencies (Breuer and Allsobrook 2019). Stronger confidence in professional competence and insight into technical and practical work processes is a logical explanation to this. Despite this, professional argumentation increases from a low to a medium level for industrial mechanics and electricians during VET. A similar pattern is seen in the use of professional specific terminology. This pattern leads us to question the influence that schools have on terminology use. Do textbooks and learning resources in school context have an impact on the salient terminology use in healthcare and less so among the industrial mechanics and electricians? However, the influence from practical work in workplaces is likely to strengthen professional use of language for both industrial mechanics and electricians. The vocabulary of healthcare workers seems to be more in line with ordinary common vocabulary and terminology, maybe because much communication is with patients and their relatives.

Our data are in line with conclusions from other studies (Guile and Young 2003; Hellne-Halvorsen 2019; Lahn and Nore 2019) that the re-contextualization of transversal generic writing competency from school to training enterprise and vice versa needs to be understood more fully. On one hand, we would predict that the 12-years' period in school with Norwegian language as a main subject, and the recent competence-based educational reform with writing as a "key competence" (Mulder 2017), would strengthen generic writing skills. On the other hand, these may be poorly integrated with vocational subjects in the learning trajectory of students and apprentices (Hertzberg and Roe, 2015; Bétrancourt et al. 2016; Neumann 2016; Parkinson et al. 2018). Also, international studies (Nägele and Stalder 2017) have identified obstacles to transfer of generic skills, such as motivation, cognition and self-regulation, social processes and organization at work. Efficiency, economy and time pressure at workplaces may hinder use and development of generic skills and the transition from school to work. Added to this, generic writing skills depend on how trainers and colleagues in workplaces facilitate such skills through guidance and instructions (Billett 2000; Neumann 2016). 
Distinct variations in the written products from three vocational professions may indicate specific and context-bound discourses, traditions and cultures (Parkinson et al. 2018). In healthcare, coherent narrative prose is the most common text formation, while industrial mechanics and electricians use a combination of prose and fragmentary texts, often supported by specific non-verbal semiotic resources. However, our analysis did not include how these forms interacted with professional competency and professional argumentation by influencing the coherence, logical structure and the intelligibility of the text. In the implementation of the COMET-model Norwegian VET-teachers resisted the international protocol for the testing by allowing the testees to be on-line (Lahn and Nore 2019). This generated by accident interesting observations that challenged the underlying plan-work-reflect rationale for using the pen and paper format in the hand-ins. The belief in textual media as superior explication devices in professional contexts compared with other semiotic resources is not warranted by recent studies of multiliteracies (Kress et al. 2001; Mills 2010). Similarly, from a somewhat different institutional angle, text-based examinations cannot be conceived as "proxies" for digitalized assessment systems that may capture very different aspects of the learning trajectories of VET-students and apprentices.

\section{Final Reflections}

The combination of generic and professional writing competencies as hybrid writing competency manifests itself differently in the three vocational professions in our study. The literacy skills of the healthcare workers are more generic, and that of industrial mechanics and electricians more profession oriented. The context for our analysis of professional writing is a test situation that very likely will be associated with a school setting - irrespective of the case-based and authentic character of the assignments. As predicted, the health care apprentices would take advantage of their expertise in a narrative format that resulted in high scores on the important dimensions or categories. Similarly, the students and apprentices in the technical vocations may have short-cut the COMET-guidelines for a holistic interpretation of the test-assignment by using a familiar written solution from tests with a more closed format. In this sense the written hand-ins could be understood not only as specific professional writing genres, but also as norms about how to respond to test situations. Thus, hybridity may be identified in terms of a large variety of patterns as situated in more or less typical literacy events (Heath 1983). In this respect two implications of our study, one didactical and one methodological, are worthy of a final reflection.

The last couple of years we have witnessed a revival of the learning journal (or blogs) as a device for bridging the world of school and work (Schwendimann et al. 2018). The overall rationale for such educational innovations has been variants of the plan, write, reflect-model, but recent reviews are highlighting the challenging character of those assignments for VET-students (Cattaneo and Aprea 2018). It is quite common to attribute their poor performances to a low competency on the generic dimensions for writing, and as pointed out by Edwards et al. (2013), the literacies associated with academic subjects are often seen as more cognitively demanding than literacy skills related to vocational subjects. These UK researchers then refer to studies that partly reverse these assumptions. In the latter case they found a larger variety of literacies. To some extent we identified similar patterns in our written hand-ins produced in a test 
environment. Thus, our exploration could be a starting point for investigating "effective scaffolds" for VET-learners that "...might lack proficiency or show reluctance for reflective writing..." (Schwendimann et al. 2018, p. 5). However, we need to question to what extent the linear conceptions of writing skills represent a barrier or a scaffold in our modelling of such assumedly boundary-crossing tools.

A valid objection to our study then is our use of a coding manual that mainly had been validated for academic texts (Skar et al. 2017) although profession-specific categories were added. On the other hand, this framework may be face valid for how the COMET-raters (as teachers, trainers, professional examiners) assessed the written achievements of the testees. As pointed out above, the overall COMET-score on holistic professional competence correlated strongly with the sub-dimension on (written) presentation of the test-solution. Still, in our focus group interviews with the COMET-raters, they reassured us that they were trained in "reading between the lines". The hyper-textual and multi-modal character of the hand-ins from students and apprentices in the technical vocations was only represented in terms of frequencies (of occurrence) and not integrated into a framework supporting a functional understanding of the text production. This extension is highly recommended given the empirical evidence above provided by Edwards et al. (2013) and useful for the development of a coding manual that is valid as an instrument for assessing writing competence in VET or a methodological foundation for designing "scaffolds" in the implementation of educational programs with learning logs and journals. However, micro-genetic studies and in-depth studies of the expertise of students and apprentices in text-production across the school / work boundaries are needed.

\section{Funding Open Access funding provided by OsloMet - Oslo Metropolitan University.}

Open Access This article is licensed under a Creative Commons Attribution 4.0 International License, which permits use, sharing, adaptation, distribution and reproduction in any medium or format, as long as you give appropriate credit to the original author(s) and the source, provide a link to the Creative Commons licence, and indicate if changes were made. The images or other third party material in this article are included in the article's Creative Commons licence, unless indicated otherwise in a credit line to the material. If material is not included in the article's Creative Commons licence and your intended use is not permitted by statutory regulation or exceeds the permitted use, you will need to obtain permission directly from the copyright holder. To view a copy of this licence, visit http://creativecommons.org/licenses/by/4.0/.

\section{References}

Andrews, R., Torgerson, C., Low, G., McGuinn, N., \& Robinson, A. (2009). Teaching argumentative nonfiction writing to 7-14 Year Olds: A systemtic Review of the Evidence of Successful Practice. Cambridge Journal of Education, 39(3), 291-310.

Baek, C., Hörmann, B., Karseth, B., Pizmony-Levy, O., Sivesind, K., \& Steiner-Khamsi, G. (2018). Policy learning in Norwegian school reform: a social network analysis of the 2020 incremental reform. Nordic Journal of Studies in Educational Policy, 4(1), 24-37. https://doi.org/10.1080/20020317.2017.1412747.

Baethge, M., \& Arends, L. (2009). Measuring vocational competencies [Council for Social and Economic Data (RatSWD)]. Working Paper Series, 95. http://ssrn.com/abstract=1452664. Accessed 12 Sep 2017.

Berge, K. L., Evensen, L. S., \& Thygesen, R. (2016). The Wheel of Writing: a model of the writing domain for teaching and assessing of writing as a key competency. The. Curriculum Journal, 27(2), 172-189. https://doi.org/10.1080/09585176.2015.1129980. 
Bétrancourt, M., Ortoleva, G., \& Billett, S. (2016). Writing for Professional Development: An Introduction. In M. Bétramncourt, G. Ortoleva \& S. Billett (Eds.), Writing for Professional Development (Bd. 32, pp. 111). Brille.

Billett, S. (2000). Guided learning at work. Journal of Workplace Learning, 12(7), 272-285. https://www. emeraldinsight.com/doi/pdfplus/10.1108/13665620010353351. Accessed 11 Apr 2018.

Bremner, S. (2017). Workplace writing. Beyond the text. Francis \& Taylor.

Breuer, E., \& Allsobrook, P. (2019). Teaching and Practising Interdiscursivity in the Professional Areas of Engineering and Health - A Qualitative Study. Hermes - Journal of Language and Communication in Business, 59, 15-32.

Breuer, E. O., Newman, S. \& Newman, J. (2016). Learning to Write as a Professional: Engineers and health Professionals in United Kingdom and Germany. In M. Bétrancourt, G. Ortoleva \& S. Billett (Eds.), Writing for Professional Development (Bd. 32, pp. 253-275). Brill.

Cattaneo, A. A. P., \& Aprea, C. (2018). Visual Technologies to Bridge the Gap Between School and Workplace in Vocational Education. In D. Ifenthaler (Ed.), Digital Workplace Learning. Bridging Formal and Informal Learning with Digital Technologies (pp. 251-270). Springer International Publishing AG. https://doi.org/10.1007/978-3-319-46215-8_14.

Charmaz, K. (2014). Constructing grounded theory: A practical guide through qualitative analysis. London: SAGE.

Coppi, A. E., Cattaneo, A., \& Gurtner, J.-L. (2019). Exploring visual languages acreoss vocational professions. International Journal for Research in Vocational Education and Training (IJRVET), 6(1), 68-96. https://doi.org/10.13152/IJRVET.6.1.4.

Davey, G. \& Fuller, A. (2013). Transcending the academic-vocational binary in England? - An exploration of the promise of hybrid qualifications. In T. Deissinger, J. Aff, A. Fuller \& C. H. Jørgensen (Eds.), Hybrid Qualifications: Structures and Problems in the Context of European Vet Policy (Bd. 10, pp. 79-111). Peter Lang.

Edwards, R., Minty, S., \& Miller, K. H. (2013). The literacy practices for assessment in the vocational curriculum - the case of Hospitality. Journal of Vocational Education \& Training, 62(2), 220-235. https://doi.org/10.1080/13636820.2013.783611.

Evensen, L. S., Berge, K. L., Thygesen, R., Matre, S., \& Solheim, R. (2016). Standards as a tool for teaching and assessing cross-curricular writing. The Curriculum Journal, 27(2), 229-245. https://doi.org/10.1080/ 09585176.2015 .1134338 .

Fraiberg, S. (2018). Multilingual and multimodal practices at a global startup: Toward a spatial approach to language and literacy in professional contexts. English for Specific Purposes, 51, 55-68. https://doi.org/ 10.1016/j.esp.2018.03.003.

Gee, J. P., \& Hayes, E. R. (2011). Language and Learning in the Digital Age. In Routledge.

Gee, J. P., Hull, G., \& Lankshear, C. (1996). The New Work Order: Behind the Language of the New Capitalism. In Allen \& Unwin.

Guile, D., \& Young, M. (2003). Transfer and Transition in Vocational Education: Some Theoretical Considerations In T. Tuomi-Gröhn \& Y. Engeström (Eds.), Between School and Work. New Perspectives on Transfer and Boundary-crossing (pp. 62-81). In Emerald Group Publishing Limited.

Halliday, M. A. K. (1973). Explorations in the Functions of Language. In Edward Arnold Publishers Ltd.

Hanemann, U. (2015). Lifelong literacy: Some trends and issues in conceptualising and operationalising literacy from a lifelong learning perspective www.unesco.org/. http://www.unesco.org/new/fileadmin/ MULTIMEDIA/FIELD/Santiago/pdf/Hanemann-Lifelong-Literacy.pdf. Accessed 1 Dec 2015.

Heath, S. B. (1983). Ways with words: Language, life and work in communities and classrooms. Cambridge Univiversity Press.

Heidrich, F., \& Schubert, K. (2019). Writing Research and Specialized Communication Studies. Hermes Journal of Language and Communication in Business, 59(1), 53-70. https://doi.org/10.7146/hjlcb.v59i1. 116984.

Hellne-Halvorsen, E.B. (2014). Skrivepraksiser i yrkesfaglige utdanningsprogrammer [Wrinting practices in Vocational Education and Training], (doctoral dissertation), University of Oslo

Hellne-Halvorsen, E. B. (2019). To kontekster - to skrivepraksiser? Skriving i skole og bedrift i fag- og yrkesopplæringen [Two contexts - two writing practices? Writing in School and Enterprise]. Nordic Journal of Vocational Education and Training, 9(1), 43-65. https://doi.org/10.3384/njvet.2242-458X. 199143

Jewitt, C., \& Kress, G. (2003). Multimodal Literacy (New Literacies and Digital Epistemologies) Peter Lang Inc. In International Academic Publishers. 
Karlsson, A.-M. (2009). Positioned by Reading and Writing. Literacy Practices, Roles, and Genres in Common Occupations. Written Communication, 26(53), 53-76. http://wcx.sagepub.com/content/26/1/ 53. Accessed 1 Dec 2015.

Karlsson, A.-M., \& Nikolaidou, Z. (2016). The Textualization of Problem Handling: Lean Discourses Meet professional Competence in Eldercare and the Manufacturing Industry. Written Communication, 33(3), 275-301. https://doi.org/10.1177/0741088316653391.

Kellogg, R. T. (2018). Professional writing expertise. In K. A. Ericsson, R. R. Hoffman, A. Kozbelt, \& A. M. Williams (Eds.), The Cambridge Handbook of Expertise and Expert Performance (pp. 413-430). Cambridge University Press. https://doi.org/10.1017/9781316480748.023.

Kress, G., Jewitt, C., Ogborn, J., \& Tsatsarelis, C. (2001). Multimodal Teaching and Learning: The Rhetorics of the Science Classroom. In Bloomsbury Academic.

Lahn, L. C., \& Nore, H. (2019). Large scale studies of holistic professional competence in vocational education and training (VET). The case of Norway. International Journal for Research in Vocational Education and Training, 7(2), 132-152. https://doi.org/10.13152/IJRVET.6.2.2

Leijten, M., Waes, V. L., Schriver, K., \& Hayes, J. (2014). Writing in the workplace: Constructing documents using multiple digital sources. Journal of Writing Research, 5(3), 285-337. https://doi.org/10.17239/jowr2014.05.03.3.

Leu, D. J., Kinzer, C. K., Coiro, J., Castek, J. \& Henry, L. A. (2017). New Literacies: A Dual-Level Theory of Changing Nature of Literacy, Instruction, and Assessment. Journal of Education, 197(2), 1-18.

Mills, K. A. (2010). A Review of the "Digital Turn" in the New Literacy Studies. Review of Educational Research, 80(2), 246-271. https://doi.org/10.3102/0034654310364401.

Mulder, M. E. (2017). Competence-based Vocational and Professional Education. Bridging the Worlds of Work and Education. Springer. https://doi.org/10.1007/978-3-319-41713-4

Nägele, C. \& Stalder, B. E. (2017). Competence and the Need for Transferable Skills. In M. Mulder (Ed.), Competence-based Vocational and Professional Education (Bd. 23, pp. 739-753). Springer International Publishing https://doi.org/10.1007/978-3-319-41713-4 34

Neumann, A. (2016). Professional Text Genres: Writing Standards in vocational Education. In M. Bétrancourt \& G. B. Ortoleva, S. Leiden - Boston, Brill. 32. (Eds.), Writing for Professional Development (Bd. 32, pp. 233-252). Brill.

Nore, H. (2015). Re-Contextualizing Vocational Didactics in Norwegian Vocational Education and Training. International Journal for Research in Vocational Education and Training, 2(3), 182-194. https://doi.org/ 10.13152/IJRVET.2.3.4

Nore, H. \& Lahn, L. Ch. (2014). Bridging the Gap between Work and Education in Vocational Education and Training. A study of Norwegian Apprenticeship Training Offices and E-Portfolio Systems. International Journal for Research in Vocational Education and Training, 1(1), 21-34. https://doi.org/10.13152/ IJRVET.1.1.2

OECD. (2009). PIAAC Literacy: A Conceptual Framework. https://doi.org/10.1787/220348414075

Ortoleva, G., \& Betrancourt, M. (2015). Collaborative writing and discussion in vocational education: Effects on learning and self efficacy beliefs. Journal of Writing Research, 7(1), 95-122. https://archive-ouverte. unige.ch/unige:92522. Accessed 12 Aug 2017.

Parkinson, J., Mackay, J., \& Demecheleer, M. (2018). Situated Learning in Acquisition of a Workplace Genre. Vocations and Learning, 11, 289-315. https://doi.org/10.1007/s12186-017-9191-x.

Rauner, F., Heinemann, L., \& Hauschildt, U. (2013). Measuring Occupational Competences: Concept, Method and Findings of the COMET Project. In L. Deitmer, U. Hauschildt, F. Rauner, \& H. Zelloth (Eds.), The Architecture of Innovative Apprenticeship (pp. 159-175). Springer Netherlands.

Sadler, T. D., \& Zeidler, D. L. (2009). Scientific Literacy, PISA, and Socioscientific Discourse: Assessment for Progressive Aims of Science Education. Journal of research in science teaching, 46(8), 909-921. https://doi.org/10.1002/tea.20327.

Schwendimann, B. A., Kappeler, G., Mauroux, L., \& Gurtner, J. L. (2018). What makes an online learning journal powerful for VET? Distinguishing productive usage patterns and effective learning strategies. Empirical Research on Vocational Education and Training, 10(9), 1-20. https://doi.org/10.1186/s40461018-0070-y.

Skar, G. B. U., Thygesen, R., \& Evensen, L. S. (2017). Assessment for Learning and Standards: A Norwegian Strategy and Its Challenges. In S. Blömeke \& J.-E. Gustafsson (Eds.), Standard Setting in Education. The Nordic Countries in an International Perspective (pp. 225-241). Cham: Springer. https://doi.org/10.1007/ 978-3-319-50856-6_13. 
Publisher's Note Springer Nature remains neutral with regard to jurisdictional claims in published maps and institutional affiliations.

\section{Affiliations}

\section{Ellen Beate Hellne-Halvorsen ${ }^{1} \cdot$ Leif Christian Lahn ${ }^{2} \cdot$ Hæge Nore $^{1}$}

1 Department of Vocational Teacher Education, Oslo Metropolitan University, Oslo, Norway

2 Department of Education, Faculty of Educational Science, Oslo University, Oslo, Norway 